\title{
Os Desafios ao Jornalismo Científico de Qualidade
}

\author{
The Challenges to Good Quality Science Journalism
}

\author{
Débora MIRANDA ${ }^{1}$ \\ Acta Med Port 2014 May-Jun;27(3):289-290
}

Palavras-chave: Jornalismo; Ciência.

Keywords: Journalism; Science.

Quer sejamos cientistas ou leigos, a ciência afecta as nossas vidas. Queremos, por isso, compreendê-la: seja a ligação entre o aquecimento global e o tufão nas Filipinas, ou a evolução tecnológica que nos permite procurar caixas negras de aviões no fundo do mar. Todos queremos - sempre com alguma urgência - compreender e controlar as ameaças à nossa saúde, desde os medicamentos que são retirados do mercado até aos casos de morte súbita em jovens.

Como membros da sociedade, temos o dever cívico de contribuir para a qualidade da informação que consumimos permanentemente. Se os especialistas não quiserem colaborar nesse processo, os não-especialistas irão fazê-lo, dando início a um fluxo de informação perigosamente incorrecto.

O jornalismo científico existe para aproximar cientistas e comunicadores. O objectivo não é o de unificar a mensagem complexa da ciência e a mensagem simplista para o público geral - mas sim o de tornar a mensagem científica mais relevante e compreensível para um público leigo. ${ }^{1}$

\section{A distância entre a ciência e o jornalismo}

A relação entre a ciência e os media existe desde os anos 80 e já foi descrita como 'azeite em água'. ${ }^{1}$ Cada grupo tem uma linguagem e interesses distintos. Num estudo realizado com mais de 1300 investigadores biomédicos do Japão, Estados Unidos, Alemanha, França e Reino Unido, mais de $90 \%$ disseram preferir colaborar com os media se o público tiver um melhor nível de literacia. ${ }^{2}$ Mas se a literacia depende da capacidade que os media têm de comunicar, é necessário que as ciências complexas, como a Medicina, ajudem a comunicação social nesse processo educativo.

Em todas as profissões existem melhores comunicadores do que outros. Da mesma forma que o paciente estima mais o médico com quem consegue aprender, o jornalista incompetente não consegue informar o seu consumidor. Segundo Fiona Fox, directora do Science Media Centre britânico, 'os media serão melhores a fazer ciência quando os cientistas cumprirem melhor o seu papel nos media'. ${ }^{3}$

\section{Médicos comunicadores e jornalistas de saúde}

Conscientes de que a exigência não pode recair apenas sobre os especialistas, há cada vez mais jornalistas que se especializam numa matéria científica e cada vez mais cientistas que reconhecem a necessidade de comunicar para públicos mais amplos. Mas o número de cursos superiores na área do jornalismo científico ainda é escasso - e muitos dos que existem fecham portas a quem não possuir formação científica prévia.

O mestrado em Science Journalism da City University London, no Reino Unido, procura aproximar os dois mundos. Entre os meus colegas constava um farmacêutico, um biólogo, uma apresentadora de rádio, um repórter de tecnologia, uma escritora interessada em psicologia, uma doutorada em genética e uma médica de família.

Neste e noutros cursos - como o mestrado em Science Communication do Imperial College London - os cientistas analisam por que uma mensagem não simplificada não será entendida para além da sua comunidade. Já os jornalistas familiarizam-se com o mundo da investigação científica e aprendem a analisar a relevância de estudos, a fim de evitar que mais pessoas se deixem confundir pelas notícias que lêem. Afinal um copo de vinho por dia pode prevenir ou provocar casos de cancro?

A relação entre cientistas e jornalistas varia entre países. O interesse público em ciência é influenciado pelos sistemas de educação nacionais, e os jornalistas de países com um sistema de investigação menos competitivo preferem utilizar fontes de países mais fortes. ${ }^{4}$ Assim se explica que, em Portugal, muitas notícias sobre ciência tenham fontes internacionais, que por vezes incluem investigadores portugueses. ${ }^{5}$

Também as práticas jornalísticas variam. Os repórteres dependem dos recursos que têm ao seu dispor. Muitos não podem ir mais longe do que adaptar (ou mesmo publicar) comunicados de imprensa, poucos têm acesso aos artigos científicos para além dos resumos - e menos ainda são os que recolhem depoimentos dos autores.

1. London School of Hygiene \& Tropical Medicine. Londres. Reino Unido.

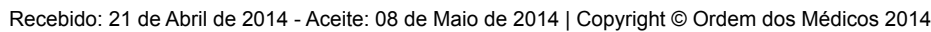




\section{O jornalismo e as particularidades da ciência}

O jornalismo científico pode ser dividido em dois tipos: reactivo e proactivo. No jornalismo reactivo procuram-se explicações simples para acontecimentos inéditos. Foi o caso do contributo de nutricionistas quando, em 2013, foi detectada carne de cavalo em embalagens de carne de vaca. Qualquer jornalista em turno pode ser confrontado com este tipo de acontecimento, colocando a qualidade da informação nas mãos dos especialistas que aceitem comentá-lo.

Já no jornalismo científico proactivo é a novidade científica que dita a agenda. Todos os dias os media nos contam que um novo estudo demonstrou como o agente $X$ pode prevenir a doença $Y$. Aqui ficamos dependentes da regra de Ingelfinger, segundo a qual só se deve divulgar o resultado de um estudo depois de ter sido publicado numa revista com arbitragem científica. ${ }^{6}$ Quando as revistas publicam resultados de interesse público, é comum divulgarem-nos através de comunicados de imprensa embargados. Durante o período de embargo, os jornalistas preparam as suas notícias para o dia em que o estudo for publicado.

No entanto é recorrente que, ao chegar à fase de disseminação dos seus projectos, os investigadores estejam já em busca de novas fontes de rendimento. Os contratos são temporários e garantir um novo projecto torna-se, naturalmente, a prioridade. Isso leva a que muitos resultados sejam publicados anos depois de os estudos terem terminado. Mas se a qualidade de uma candidatura passa pelo impacto que o estudo terá nas nossas vidas, não será um dever ético comunicar os resultados para que estes possam ser implementados rapidamente?

Mesmo quando há recursos para disseminação jornalística, muitos investigadores hesitam. Sentem não ter controlo sobre o processo e criticam muitos jornalistas por serem 'incorrectamente citados' e não poderem aprovar o artigo antes da sua publicação. Muitos também desconhecem que, geralmente, os títulos das notícias não são escritos pelos repórteres que os entrevistaram, mas sim pelos

\section{REFERÊNCIAS}

1. Peters HP. Gap between science and media revisited: scientists as public communicators. Proc Natl Acad Sci USA. 2013;110:14102-9.

2. Peters HP, Brossard D, de Cheveigné S, Dunwoody S, Kallfass M, Miller $\mathrm{S}$, et al. Science communication. Interactions with the mass media. Science. 2008;321:204-5.

3. Callaway E. Science media: centre of attention. Nature. 2013;499:1424.

4. Bentley P, Kyvik S. Academic staff and public communication: a survey editores que fecham os jornais. Os jornalistas precisam de relações saudáveis com as suas fontes, mas facto é que as notícias sobre ciência necessitam de ter interesse humano e de ser simplificadas - sob risco de não serem consumidas.

\section{Os benefícios para a comunidade científica}

Apesar das hesitações, os investigadores sabem que a sua visibilidade nos media tem vantagens. Também assim se garante apoio público e político para as universidades e revistas científicas. Uma relação bem sucedida passou a ser aquela que comunicou ao público uma mensagem de qualidade e que alertou possíveis financiadores.

Por fim, não devemos subestimar o papel dos departamentos de comunicação das organizações científicas, que funcionam (ou deveriam funcionar) como mediadores entre cientistas e jornalistas. A probabilidade de um professor ser contactado por um meio de comunicação social é maior se a universidade promover o seu trabalho e se este for publicado numa revista de prestígio.

Em suma, o jornalismo científico requer um trabalho colaborativo, mas complexo, entre jornalistas, revistas, financiadores, universidades e, acima de tudo, os que fazem ciência. O objectivo é o de dar à sociedade a informação a que tem direito e, simultaneamente, educá-la sobre o processo contínuo da ciência - que não se faz de um só estudo nem de uma só notícia. Assim se explica que a qualidade deste tipo de jornalismo passe muitas vezes pela inclusão da frase: 'São precisos mais estudos para confirmar esta teoria'.

\section{CONFLITOS DE INTERESSE}

A autora declara não ter qualquer conflito de interesse relativamente ao presente artigo.

\section{FONTES DE FINANCIAMENTO}

Este trabalho não recebeu qualquer contribuição, subsídio ou bolsa.

of popular science publishing across 13 countries. Public Underst Sci. 2011;20:48-63.

5. Agência Lusa. Cientista português cria técnica para detecção precoce do cancro. Público 2013. [consultado 2014 Mar 10]. Disponível em: http://tinyurl.com/pblrzwm.

6. Atmen LK. The Ingelfinger rule, embargoes, and journal peer review Part 1. Lancet. 1996;9012:1382-6. 


\section{Os Desafios ao Jornalismo Científico de Qualidade}

Acta Med Port 2014:27:289-290

Publicado pela Acta Médica Portuguesa, a Revista Científica da Ordem dos Médicos

Av. Almirante Gago Coutinho, 151

1749-084 Lisboa, Portugal.

Tel: +351218428 215

E-mail: submissao@actamedicaportuguesa.com

www.actamedicaportuguesa.com

ISSN:0870-399X | e-ISSN: 1646-0758

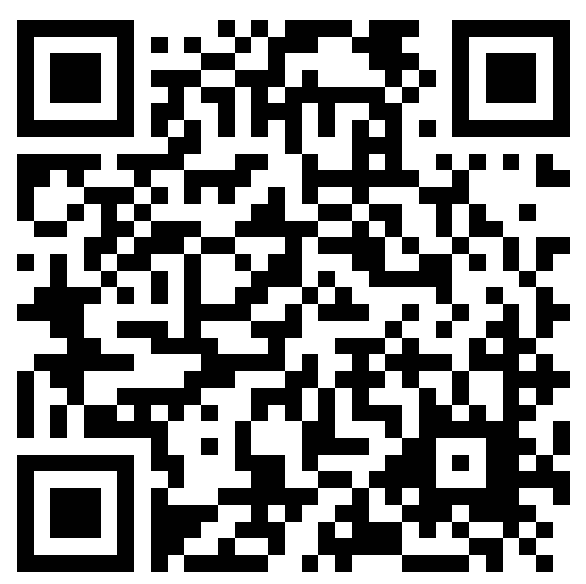

